\title{
Single-centre Experience of Use of Radium 223 with Clinical Outcomes Based on Number of Cycles and Bone Marrow Toxicity
}

\author{
SEEMA DADHANIA ${ }^{1 *}$, ROBERTO ALONZI $^{1 *}$, SUZANNE DOUGLAS $^{2}$, ANDREW GOGBASHIAN $^{3}$, \\ ROB HUGHES ${ }^{1}$, DANOOB DALILI ${ }^{3}$, NIKHIL VASDEV ${ }^{4}$, JIM ADSHEAD ${ }^{4}$, TIM LANE ${ }^{4}$, \\ CHARLOTTE WESTBURY ${ }^{1}$, NICOLA ANYAMENE ${ }^{1}$, PETE OSTLER $^{1}$, PETER HOSKIN $^{1}$ and ANAND SHARMA ${ }^{1}$ \\ Departments of ${ }^{1}$ Oncology, and ${ }^{2}$ Nuclear Medicine, Mount Vernon Cancer Centre, \\ Mount Vernon Hospital, Northwood, U.K.; \\ ${ }^{3}$ Department of Radiology, Paul Strickland Scanner Centre, Mount Vernon Cancer Centre, \\ Mount Vernon Hospital, Northwood, U.K.; \\ ${ }^{4}$ Department of Urology and Surgery, Lister Hospital, East and North Herts NHS Trust, Stevenage, U.K.
}

\begin{abstract}
Background: Bone is the most common site of metastatic disease in advanced prostate cancer. Radium-223 $\left({ }^{223} \mathrm{Ra}\right)$ is a calcium-mimetic alpha-particle emitter, which has been shown to have activity in prostate cancer with clinical benefit in patients with symptomatic bone metastasis. The recommended schedule is six cycles of ${ }^{223} \mathrm{Ra}, 5 \mathrm{kBq} / \mathrm{kg}$, at 4-weekly intervals. Although previous studies have assessed clinical outcomes in patients who received six cycles of $\mathrm{Ra}^{223}$, there is very little information about outcomes of patients receiving fewer courses of treatment. Patients and Methods: Patients with hormone-refractory metastatic prostate cancer treated from May 2014 to August 2016 were included in this retrospective study. A total of 113 patients were identified with a median age of 76 (range $=52$ 92) years. The median number of cycles administered was 5 (range=1-6) with 54 (48\%) completing six cycles of treatment. Eighty-five patients $(75 \%)$ received ${ }^{223}$ Ra prior to docetaxel chemotherapy and 28 (25\%) received it after receiving docetaxel. Results: Eleven patients developed grade 2/3 thrombocytopenia, and none of these received further ${ }^{223}$ Ra. Only $25 \%$ of patients who had a haemoglobin level of $10 \mathrm{~g} / \mathrm{dl}$ or below at the start of the treatment were able to complete six courses of ${ }^{223} \mathrm{Ra}$. Of the patients who completed fewer than six cycles of ${ }^{223} \mathrm{Ra}$ (1-5 cycles), the
\end{abstract}

\footnotetext{
*These Authors contributed equally to this study.

Correspondence to: Dr. Anand Sharma, Department of Oncology, Mount Vernon Cancer Centre, Northwood, A6 2RN, U.K. E-mail: anand.sharma3@nhs.net
}

Key Words: Prostate cancer, bone metastasis, radium 223, pain. survival was 121 days, compared to 398 days in men who received six cycles (odds ratio $(O R)=4.767,95 \%$ confidence internal $(C I)=1.07-21.25 ; p=0.0005)$. Conclusion: Careful selection of patients is essential to obtain good clinical outcomes from ${ }^{223} R$ a therapy. When fewer than six cycles were delivered then a beneficial survival effect was not seen.

Prostate cancer is the second most common cancer in men, with a worldwide incidence of 1.1 million new cases/year (1, 2). The treatment of metastatic prostate cancer has evolved with the use of docetaxel chemotherapy and third-generation endocrine agents such as abiraterone and enzalutamide (37). Since the first trials with mitoxantrone plus prednisolone, numerous agents have been found to improve outcomes for patients with this disease. Bone is the most common site of metastasis in prostate cancer and leads to an increased risk of skeletal-related events which include pathological fractures, spinal cord/nerve root compression, limited mobility, increased morbidity, hypercalcaemia, increased pain and dependence on opioids. These can have a serious impact on quality of life and in turn affect survival in patients with advanced disease $(8,9)$.

Newer bone-targeted therapies with different mechanisms of action, such as zolendronate and denosumab, are significant additions to the management of prostate cancer (10).

Radium-223 $\left({ }^{223} \mathrm{Ra}\right)$ is a first in its class calcium-mimetic alpha-particle emitter which has been shown to have activity in prostate cancer, with clinical benefit in patients with symptomatic bone metastasis. It has a half-life of 11.43 days and is taken up preferentially in areas of high bone turnover, particularly around bony metastases. ${ }^{223} \mathrm{Ra}$ is incorporated into bone where it substitutes the calcium in calcium hydroxyl apatite (11). This alpha-emitter has high linear 
energy transfer, causing double-stranded breaks in the DNA, resulting in its antitumour effects (12).

${ }^{223} \mathrm{Ra}$ is the first bone-targeted agent used in prostate cancer which has been shown to lead to an improvement in survival. In the pivotal phase III ALSYMPCA study, comparing placebo with $\mathrm{Ra}^{223}$ in patients with metastatic prostate cancer with two or more bone metastases, this drug significantly improved survival from 11.3 to 14.3 months. These patients received six injections of ${ }^{223} \mathrm{Ra}$ at $50 \mathrm{kBq} / \mathrm{kg}$ body weight every 4 weeks, with improvement in the time to the first skeletal symptomatic event [median $=15.6$ months vs. 9.8 months; hazard ratio $(\mathrm{HR})=0.66,95 \%$ confidence interval $(\mathrm{CI})=0.52-0.83 ; p=0.00037](13) .{ }^{223} \mathrm{Ra}$ was well tolerated, with similar haematological adverse events in both groups and one grade 5 thrombocytopenia (14).

As far as we are aware, there are no trials specifically comparing the safety and efficacy of ${ }^{223} \mathrm{Ra}$ in patients who received fewer than six cycles. Therefore, a retrospective review was undertaken of all patients receiving at least one cycle of ${ }^{223} \mathrm{Ra}$ between May 2014 and August 2016. Patients were referred from six district general hospitals in the surrounding region, servicing a catchment population of 2.25 million people.

\section{Patients and Methods}

Eligibility for ${ }^{223} \mathrm{Ra}$ via the Cancer Drugs Fund was based on that of the ALSYMPCA trial (13). Patients were aged 18 years or older with histologically or cytologically confirmed metastatic prostate cancer, proven skeletal metastases on imaging and no lung, liver or brain metastases, although small-volume lymph node metastases were allowed. An Eastern Cooperative Oncology Group (ECOG) performance-status score of 0-2, an estimated life expectancy of 6 months or longer, and adequate haematological, renal and liver function were required at referral.

Each cycle of ${ }^{223} \mathrm{Ra}$ was preceded by a full blood count and prostate-specific antigen (PSA) determination, record of the patient's current pain score using a validated 0-10 pain numeric rating scale, and a review by a member of the nuclear medicine team. The 11-point numeric pain rating scale used is a onedimensional measure of pain intensity in adults. It ranges from ' 0 ' representing one pain extreme (i.e. "no pain") to ' 10 ' representing the other pain extreme (i.e. "pain as worse as you can imagine") (15). The electronic health records of patients were reviewed to look for incidence of haematological and other adverse events; treatment toxicities were graded according to the Common Terminology Criteria for Adverse Events version 4.03 (16). Although ethical approval was not required for this service evaluation audit, this study was registered with the East and North Hertfordshire NHS trust (ID:10215).

Statistical analyses. Prism 6 (GraphPad software, USA) was used for statistical analysis and for graphical presentation. Chi-square test and Fisher's exact test were used to determine the association between the categorical variables. Overall survival was calculated using the Kaplan-Meier method. Overall survival was measured from baseline to death. The HR and its $95 \%$ CI for variables were determined by Cox proportional hazards model. All statistical tests
Table I. Baseline demographics and clinical profile of the study population $(n=113)$.

\begin{tabular}{ll}
\hline Characteristic & Value \\
\hline Age, years & \\
$\quad$ Median (range) & \\
$76(52-92)$ & $61(54)$ \\
$\quad>75$ Years, $\mathrm{n}(\%)$ & $5(1-6)$ \\
No. of cycles & \\
$\quad$ Median (range) & $21(9-36)$ \\
Follow-up, months & \\
$\quad$ Median (range) & $2(1-4)$ \\
No. of previous lines of treatment & \\
$\quad$ Median (range) & $28(25)$ \\
Prior docetaxel, $\mathrm{n}(\%)$ & $85(75)$ \\
$\quad$ Yes & $11(10)$ \\
$\quad$ No & $15(13)$ \\
Extent of disease, $\mathrm{n}(\%)$ & $67(60)$ \\
$\quad<6$ Metastases & \\
$6-20$ Metastases & $20(17)$ \\
$\quad>20$ Metastases & \\
Superscan* & \\
$\mathrm{n}(\%)$ &
\end{tabular}

*Bone scan demonstrating diffusely increased skeletal radioisotope uptake relative to soft tissue in association with absent or faint renal activity (absent kidney sign).

were two-sided by default, and the significance level was set to 0.05 unadjusted for multiple comparisons.

\section{Results}

One hundred and thirteen patients received a total of 495 cycles of ${ }^{223} \mathrm{Ra}$ between May 2014 and August 2016, with a median follow-up time of 21 (range=9-36) months. The majority of patients had been heavily pre-treated, receiving ${ }^{223} \mathrm{Ra}$ as third line or higher. All patients fulfilled the initial criteria having an absolute neutrophil count $>1500 / \mathrm{ml}$, and platelet count $>100,000 / \mathrm{ml}$. Table I shows the patient demographics.

Of the 113 patients, $54(48 \%)$ received the full dose of six cycles of ${ }^{223} \mathrm{Ra}, 14(12 \%)$ patients received five and 45 (40\%) patients received four cycles or less. Pain was assessed prior to each cycle and there was a statistically significant reduction in pain between the first and final ${ }^{223} \mathrm{Ra}$ treatment $(p<0.0001)$, as assessed using a 0-10 pain numeric rating scale (Figure $1 \mathrm{~A}$ and $\mathrm{B}$ ). PSA was recorded in all patients prior to the first and final cycle and the mean PSA showed a downward trend (Figure 1C).

The incidence of haematological events was low, with grade 3 or 4 anaemia seen in $6 \%$, grade 2 thrombocytopaenia in $6 \%$, grade 3 or 4 thrombocytopenia in $2 \%$ and no documented episodes of neutropenia or neutropenic sepsis. No patient developing grade 2 thrombocytopenia went on to complete six cycles of ${ }^{223} \mathrm{Ra}$. Seventy-five percent of patients who had grade 2 anaemia $(\leq 10.0 \mathrm{~g} / \mathrm{dI})$ at the start of 

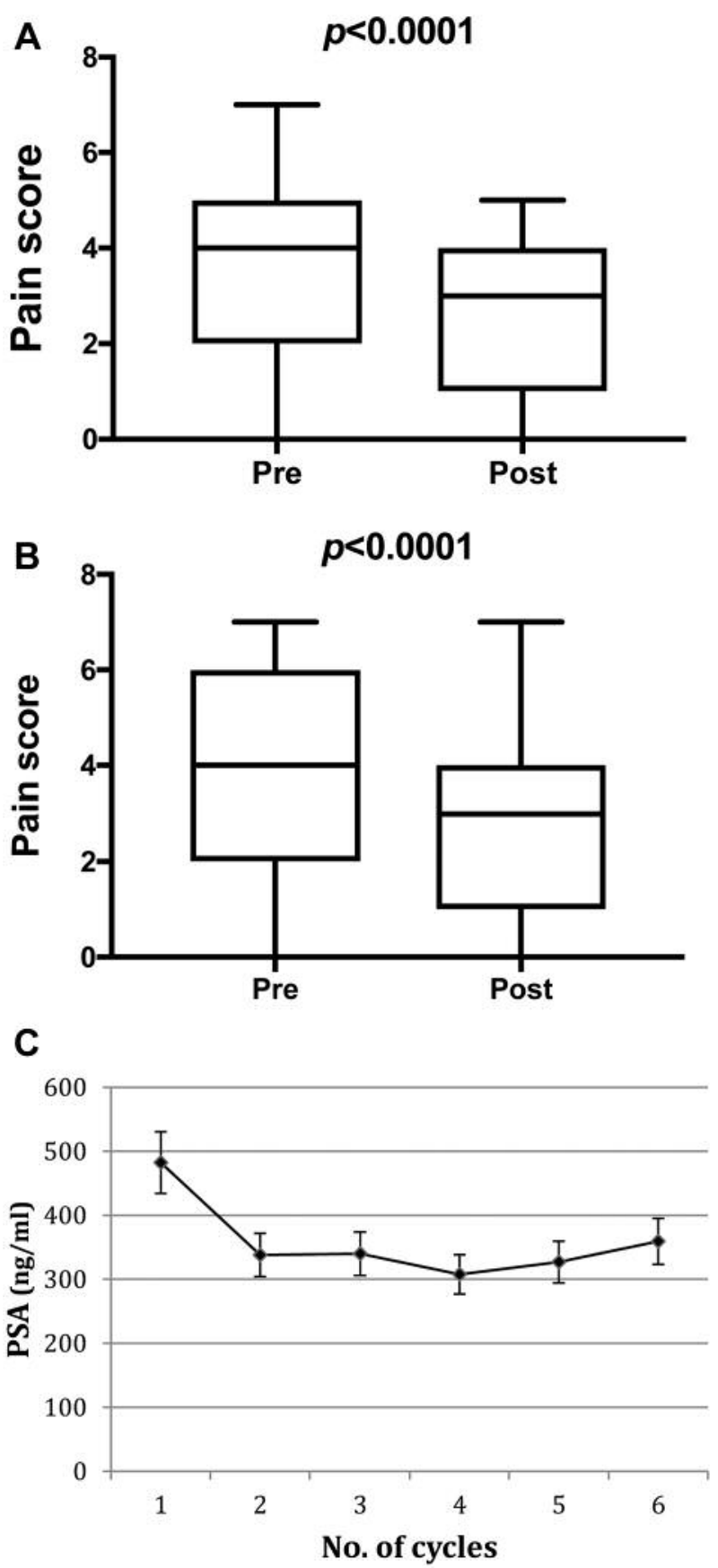

Figure 1. Pain score and prostate-specific antigen (PSA) response in patients who received ${ }^{223} \mathrm{Ra}$. Pain score before and after therapy in patients who had A: six cycles and B: fewer than six cycles of ${ }^{223} \mathrm{Ra}$ therapy. C: Mean PSA response to ${ }^{223} R a$.

their treatment did not complete six cycles. At least one hospitalisation was seen in $18 \%$ of patients (see Table II).

Seventy-five percent of patients did not have prior docetaxel therapy, (Figure 2A); this had no bearing on survival, with both groups showing a similar survival benefit
Table II. Bone marrow toxicity, and hospitalisation history of patients on ${ }^{223}$ Ra therapy ( $n=113$ patients).

\begin{tabular}{lcccc}
\hline & \multicolumn{4}{c}{ CTCAE grade } \\
\cline { 2 - 5 } Toxicity & $2, \mathrm{n}$ & $3, \mathrm{n}$ & $4, \mathrm{n}$ & $3+4, \mathrm{n}(\%)$ \\
\hline Neutropenia & 4 & 0 & 0 & $0(0)$ \\
Anaemia & 42 & 6 & 0 & $6(5)$ \\
Thrombocytopenia & 7 & 2 & 0 & $2(2)$ \\
Number of patients with & \multicolumn{5}{c}{$21(18)$} \\
one hospitalisation (\%) & \multicolumn{5}{c}{31} \\
Total number of hospitalisations & \multicolumn{5}{c}{239} \\
Total number of days hospitalised & \multicolumn{5}{c}{} \\
\hline
\end{tabular}

n, Number of events.

$(\mathrm{HR}=1.09 ; 95 \% \mathrm{CI}=0.67$ to $1.77, p<0.72)$ (Figure 2B). Forty-eight percent of patients completed six courses of ${ }^{223} \mathrm{Ra}$. These patients had longer survival compared to those receiving five or fewer cycles (398 vs. 121 days) $(\mathrm{OR}=4.767$; $95 \% \mathrm{CI}=1.02$ to $21.25, p<0.0005$ ) (Figure $2 \mathrm{C}$ ).

\section{Discussion}

${ }^{223} \mathrm{Ra}$ has been shown to provide both symptomatic and survival benefit in metastatic castration-resistant prostate cancer with predominantly bone metastases when compared with placebo; it has been well integrated into treatment owing to its manageable side-effect profile, safety and ease of administration.

The aim of this study was to evaluate this relatively new therapeutic option following the published ALSYMPCA trial showing a median survival of 14.9 months (14). Of the 113 patients referred for ${ }^{223} \mathrm{Ra}$ with a median age of 76 years, $48 \%$ of patients completed six cycles, which is lower than the 58\% seen in ALSYMPCA. The median survival in patients who completed six cycles in our study was significantly shorter at 13.1 vs. 14.9 months in ALSYMPCA $(p<0.0005)$. Adverse haematological events were similar to those reported, with only $6 \%$ of patients developing a grade 3 or 4 anaemia, 2\% developing grade 3 or 4 thrombocytopaenia and no episodes of neutropenia, suggesting a good safety profile with minimal haematological toxicity.

In an exploratory analysis, patients treated with ${ }^{223} \mathrm{Ra}$ with a baseline $\mathrm{Hb}$ level of $10 \mathrm{~g} / \mathrm{dI}$ or greater had improved overall survival versus those with $10 \mathrm{~g} / \mathrm{dl}$ or less (17 vs. 10 months) (17). In this study, $75 \%$ of patients commencing ${ }^{223} \mathrm{Ra}$ with $\mathrm{Hb}$ of $10 \mathrm{~g} / \mathrm{dl}$ or less did not complete six cycles of ${ }^{223} \mathrm{Ra}$. Furthermore, patients who completed six cycles had longer survival compared to those having five cycles or fewer. To our knowledge, it is unknown whether patients with metastatic prostate cancer have any benefit from ${ }^{223} \mathrm{Ra}$ if they receive fewer than six cycles of treatment. Therefore, this 

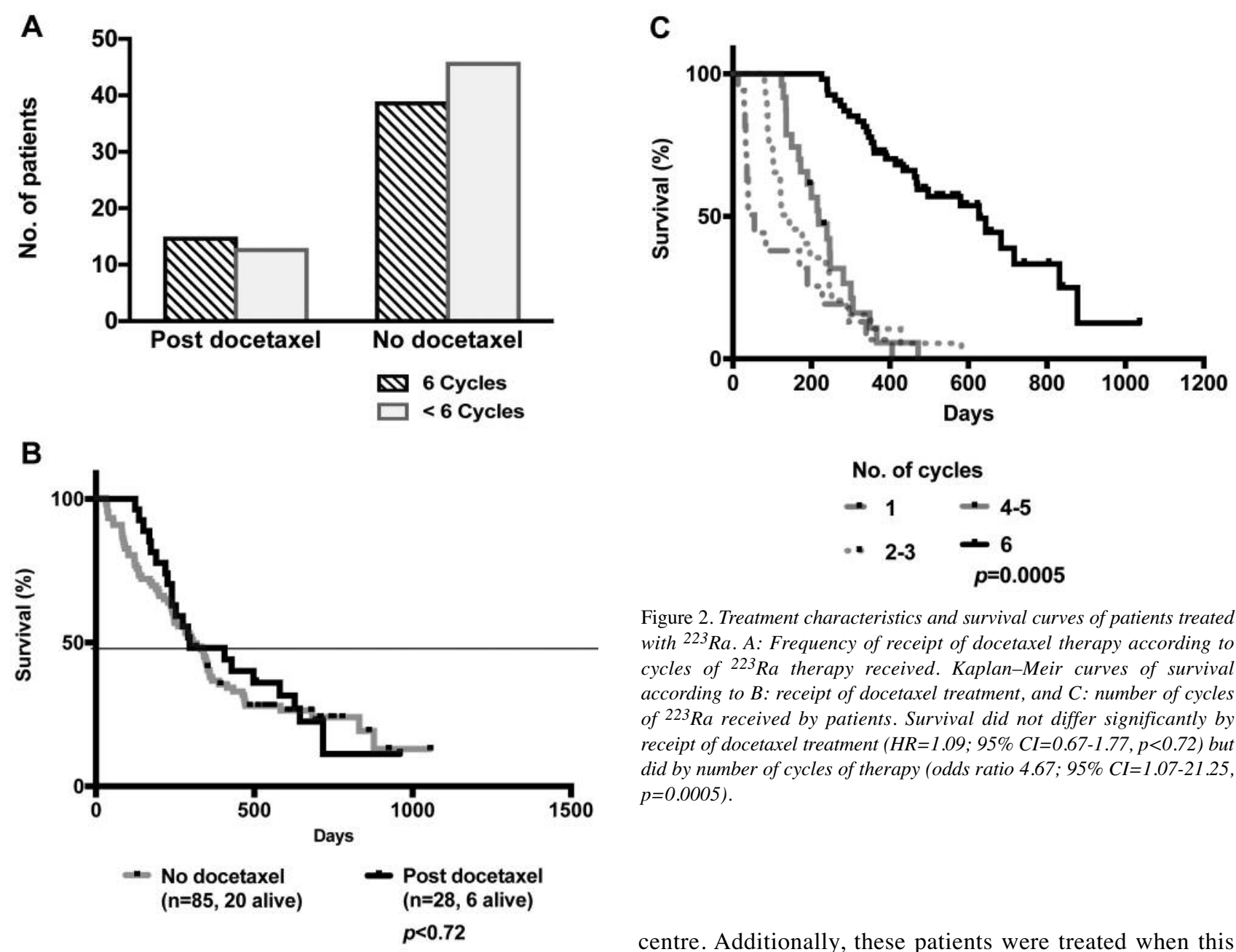

Figure 2. Treatment characteristics and survival curves of patients treated with ${ }^{223} \mathrm{Ra}$. A: Frequency of receipt of docetaxel therapy according to cycles of ${ }^{223} R$ a therapy received. Kaplan-Meir curves of survival according to B: receipt of docetaxel treatment, and C: number of cycles of ${ }^{223} R$ a received by patients. Survival did not differ significantly by receipt of docetaxel treatment ( $H R=1.09 ; 95 \% C I=0.67-1.77, p<0.72)$ but did by number of cycles of therapy (odds ratio 4.67; 95\% CI=1.07-21.25, $p=0.0005$ ).

information can be taken as a risk stratification tool when deciding on the eligibility for future treatments in metastatic prostate cancer.

Studies have been exploring the use of ${ }^{223} \mathrm{Ra}$ in clinical practice associated with various variables, and various patient characteristics. McKay et al. described factors associated with therapy completion including previous sipuleucel-T treatment, haemoglobin and neutrophil count, alkaline phosphatase and lactate dehydrogenase levels, and previous abiraterone and enzalutamide treatment (18). Pei Song et al. described a similar clinical benefit in different age groups of patients treated with ${ }^{223} \mathrm{Ra}$, however, with a higher rate of anaemia in younger patients, which could be due to a higher proportion of younger patients being treated with docetaxel ( $<72$ years age) (19). In another retrospective analysis of 25 patients treated with ${ }^{223} \mathrm{Ra}$, only six received the six scheduled doses of this treatment, and advancing soft-tissue disease was the primary reason for cessation of therapy (20).

This study does have several limitations. This was a retrospective study, involving ${ }^{223} \mathrm{Ra}$ treatment at a single

centre. Additionally, these patients were treated when this treatment had just been approved, hence experience was limited. Many patients had end-stage disease, were heavily treated, and had extensive bone disease. The small sample size and bias, especially ascertainment bias, that is introduced into any cohort study, limit this study.

\section{Conclusion}

To our knowledge, no prior studies have evaluated outcomes in patients, based on the number of treatment cycles of ${ }^{223} \mathrm{Ra}$ administered in patients with prostate cancer. Careful selection of patients is essential to achieve good clinical outcomes and avoid use of treatment in those for whom there is less chance of completing six cycles of therapy. We propose reviewing $\mathrm{Hb}$ level at the start of treatment, and monitoring platelet count closely during cycles, as surrogate markers to predict whether patients are likely to complete six cycles of ${ }^{223} \mathrm{Ra}$ therapy.

\section{Acknowledgements}

Dr A Sharma is funded partly by the Cancer Treatment and Research Trust (CTRT). 


\section{Disclosure}

The Authors have declared no conflicts of interest in regard to this study.

\section{References}

1 Siegel RL, Miller KD and Jemal A: Cancer statistics, 2016. CA Cancer 66: 7-30, 2016.

2 Torre LA, Bray F, Siegel RL, Ferlay J, Lortet-Tieulent J and Jemal A: Global cancer statistics, 2012. CA Cancer J 65: 87-108, 2015.

3 Fizazi K, Tran N, Fein L, Matsubara N, Rodriguez-Antolin A, Alekseev BY, Ozguroglu M, Ye D, Feyerabend S, Protheroe A, De Porre P, Kheoh T, Park YC, Todd MB, Chi KN and LATITUDE Investigators: Abiraterone plus prednisone in metastatic, castration-sensitive prostate cancer. N Engl J Med 377: 352-360, 2017.

4 James ND, Sydes MR, Clarke NW, Mason MD, Dearnaley DP, Spears MR, Ritchie AW, Parker CC, Russell JM, Attard G, de Bono J, Cross W, Jones RJ, Thalmann G, Amos C, Matheson D, Millman R, Alzouebi M, Beesley S, Birtle AJ, Brock S, Cathomas R, Chakraborti P, Chowdhury S, Cook A, Elliott T, Gale J, Gibbs S, Graham JD, Hetherington J, Hughes R, Laing R, McKinna F, McLaren DB, O'Sullivan JM, Parikh O, Peedell C, Protheroe A, Robinson AJ, Srihari N, Srinivasan R, Staffurth J, Sundar S, Tolan S, Tsang D, Wagstaff J, Parmar MK and STAMPEDE investigators: Addition of docetaxel, zoledronic acid, or both to first-line longterm hormone therapy in prostate cancer (STAMPEDE): survival results from an adaptive, multiarm, multistage, platform randomised controlled trial. Lancet 387: 1163-1177, 2016.

5 Gravis G, Boher JM, Joly F, Soulie M, Albiges L, Priou F, Latorzeff I, Delva R, Krakowski I, Laguerre B, Rolland F, Theodore C, Deplanque G, Ferrero JM, Culine S, Mourey L, Beuzeboc P, Habibian M, Oudard S, Fizazi K and Getug: Androgen deprivation therapy (ADT) plus docetaxel versus ADT alone in metastatic non castrate prostate cancer: impact of metastatic burden and long-term survival analysis of the randomized phase 3 GETUG-AFU15 Trial. Eur Urol 70: 256-262, 2016.

6 Ryan CJ, Smith MR, de Bono JS, Molina A, Logothetis CJ, de Souza P, Fizazi K, Mainwaring P, Piulats JM, Ng S, Carles J, Mulders PF, Basch E, Small EJ, Saad F, Schrijvers D, Van Poppel H, Mukherjee SD, Suttmann H, Gerritsen WR, Flaig TW, George DJ, Yu EY, Efstathiou E, Pantuck A, Winquist E, Higano CS, Taplin ME, Park Y, Kheoh T, Griffin T, Scher HI, Rathkopf DE and COU-AA-302 Investigators: Abiraterone in metastatic prostate cancer without previous chemotherapy. N Engl J Med 368: 138-148, 2013.

7 Scher HI, Fizazi K, Saad F, Taplin ME, Sternberg CN, Miller K, de Wit R, Mulders P, Chi KN, Shore ND, Armstrong AJ, Flaig TW, Flechon A, Mainwaring P, Fleming M, Hainsworth JD, Hirmand M, Selby B, Seely L, de Bono JS and AFFIRM Investigators: Increased survival with enzalutamide in prostate cancer after chemotherapy. N Engl J Med 367: 1187-1197, 2012.

8 Broder MS, Gutierrez B, Cherepanov D and Linhares Y: Burden of skeletal-related events in prostate cancer: unmet need in pain improvement. Support Care Cancer 23: 237-247, 2015.

9 Bubendorf L, Schopfer A, Wagner U, Sauter G, Moch H, Willi N, Gasser TC and Mihatsch MJ: Metastatic patterns of prostate cancer: An autopsy study of 1,589 patients. Hum Pathol 31: 578583,2000
10 Fizazi K, Carducci M, Smith M, Damiao R, Brown J, Karsh L, Milecki P, Shore N, Rader M, Wang H, Jiang Q, Tadros S, Dansey $\mathrm{R}$ and Goessl C: Denosumab versus zoledronic acid for treatment of bone metastases in men with castration-resistant prostate cancer: A randomised, double-blind study. Lancet 377: 813-822, 2011.

11 Henriksen G, Breistol K, Bruland OS, Fodstad O and Larsen RH: Significant antitumor effect from bone-seeking, alphaparticle-emitting (223) Ra demonstrated in an experimental skeletal metastases model. Cancer Res 62: 3120-3125, 2002.

12 Liepe K and Shinto A: From palliative therapy to prolongation of survival: (223)RaCl2 in the treatment of bone metastases. Ther Adv Med Oncol 8: 294-304, 2016.

13 Sartor O, Coleman R, Nilsson S, Heinrich D, Helle SI, O'Sullivan JM, Fossa SD, Chodacki A, Wiechno P, Logue J, Widmark A, Johannessen DC, Hoskin P, James ND, Solberg A, Syndikus I, Vogelzang NJ, O'Bryan-Tear CG, Shan M, Bruland OS and Parker C: Effect of radium-223 dichloride on symptomatic skeletal events in patients with castration-resistant prostate cancer and bone metastases: results from a phase 3, double-blind, randomised trial. Lancet Oncol 15: 738-746, 2014.

14 Parker C, Nilsson S, Heinrich D, Helle SI, O’Sullivan JM, Fossa SD, Chodacki A, Wiechno P, Logue J, Seke M, Widmark A, Johannessen DC, Hoskin P, Bottomley D, James ND, Solberg A, Syndikus I, Kliment J, Wedel S, Boehmer S, Dall'Oglio M, Franzen L, Coleman R, Vogelzang NJ, O'Bryan-Tear CG, Staudacher K, Garcia-Vargas J, Shan M, Bruland OS, Sartor O and AFFIRM Investigators: Alpha emitter radium-223 and survival in metastatic prostate cancer. N Engl J Med 369: 213-223, 2013.

15 Jensen MP, Karoly P and Braver S: The measurement of clinical pain intensity: a comparison of six methods. Pain 27: 117-126, 1986.

16 United States, Department of Health and Human Services, National Institutes of Health, National Cancer Institute(nci) Common Terminology Criteria for Adverse Events (CTCAE) Bethesda, MD: NCI; 2010. Ver. 4.03.

17 Weinfurt KP, Li Y, Castel LD, Saad F, Timbie JW, Glendenning GA and Schulman KA: The significance of skeletal-related events for the health-related quality of life of patients with metastatic prostate cancer. AnnOncol 16: 579-584, 2005.

18 McKay RR, Jacobus S, Fiorillo M, Ledet EM, Cotogna PM, Steinberger AE, Jacene HA, Sartor O and Taplin ME: Radium223 use in clinical practice and variables associated with completion of therapy. Clin Genitourin Cancer 15: e289-e298, 2017.

19 Song YP, Ellis T, Walshaw R, Mbanu P, Parikh O, Logue J and Choudhury A: Comparing clinical outcomes for radium-223: Do older patients do worse? Int J Radiat Oncol Biol Phys 98: 955957, 2017.

20 Jadvar H, Challa S, Quinn DI and Conti PS: One-year postapproval clinical experience with radium-223 dichloride in patients with metastatic castrate-resistant prostate cancer. Cancer Biother Radiopharm 30: 195-199, 2015
Received June 22, 2018

Revised July 22, 2018

Accepted July 23, 2018 